\title{
ANÁLISE DAS SETE FERRAMENTAS ESTATÍSTICAS DA QUALIDADE UTILIZADAS NOS SITEMAS PRODUTIVOS
}

\author{
Valéria Vasconcelos Perez ${ }^{1}$ \\ Adriana Amaro Diacenco ${ }^{2}$ \\ Paulo Henrique Paulista ${ }^{3}$
}

\begin{abstract}
Resumo: Com o acelerado crescimento industrial, a competitividade pela eficiência da produtividade e pela disputa de clientes, fez que com as organizações tomassem a qualidade como sinônimo de sua sobrevivência ou fracasso. Com isso, a busca por métodos que auxiliem na detecção de anomalias e melhoria dos processos produtivos. As principais ferramentas estatísticas da qualidade são muito utilizadas para o auxílio na identificação de anomalias, tal como a eliminação das mesmas e ainda proporcionam ao gerente de produção a tomar decisões para a melhoria do processo. Este artigo objetiva buscar conhecimento das ferramentas estatísticas a partir da revisão da literatura. A partir da abordagem da revisão da literatura, foi feita uma pesquisa descritiva, sendo abordado dois estudos de casos que utilizaram as ferramentas da qualidade enfatizando qual ferramenta fora utilizada, sendo estas o Diagrama de Causa e Efeito, Diagrama de Dispersão, Gráfico de Pareto, Histograma, Folha de Verificação, Gráfico de Controle e qual foi a principal função das mesmas. Por fim, de acordo com os resultados analisados é possivel afirmar que as ferramentas estatísticas da qualidade foram utilizadas corretamente e ainda as mesmas foram aptas para a análise do processo, tal como indicar possíveis oportunidades de melhorias do processo.
\end{abstract}

Palavras-chave: Ferramentas da qualidade; Estatística; Qualidade.

\footnotetext{
1 Engenharia de Produção/FEPI, Brasil. E-mail: valperez1992@gmail.com.

2 Engenharia de Produção/FEPI, Brasil. E-mail: adriana_aadiacenco@yahoo.com.br.

3 Engenharia de Produção/FEPI, Brasil. E-mail: paulohpaulista@gmail.com.
} 